Copyright (C) 2021 University of Bucharest Printed in Romania. All rights reserved

ISSN print: $1224-5984$

ISSN online: $2248-3942$
Rom Biotechnol Lett. 2021; 26(5): 2994-3001

doi: $10.25083 / \mathrm{rbl} / 26.5 / 2994.3001$

Received for publication, October, 16, 2020

Accepted, August, 6, 2021

Original paper

\title{
Purification and characterization of thermo-alkaline stable lipase from Bacillus coagulans and its compatibility with commercially available detergents
}

\begin{abstract}
ABDULLAH A. AL-GHANAYEM
Department of Clinical Laboratory Sciences, College of Applied Medical Sciences Shaqra University, Shaqra 11961 Kingdom of Saudi Arabia.
\end{abstract}

\begin{abstract}
Thermo-alkaline stable lipase producing B. coagulans was isolated and identified by $16 \mathrm{~S}$ rRNA sequencing. The lipase production was optimized using different growth parameters. The enzyme was purified and characterized in terms of $\mathrm{pH}$, temperature, solvents, heavy metal ions and inhibitors. Compatibility with commercially available detergents was also studied. The isolate showed maximum lipase production at $37^{\circ} \mathrm{C}$; $\mathrm{pH}$ of 9 within $48 \mathrm{~h}$. Addition of magnesium chloride increased lipase production. Sephadex G-100 chromatography was used to purify lipase. The enzyme showed maximum activity at $\mathrm{pH} 8$ of $30^{\circ} \mathrm{C}$. Lipase form $B$. coagulans was active at a wide range of temperature between $30-70{ }^{\circ} \mathrm{C}$. It was stable in most of the solvents at a concentration 5 and $10 \%$, except dimethyl sulfoxide (DMSO) and methanol. Iodoacetic acid (IAA) and p-chloromercuribenzoic acid $(p C M B)$ had an inhibitory effect on lipase. The lipase was compatible with commercially available detergents that increased the brightness and whiteness of the tested cotton fabrics. Lipase from $B$. coagulans with alkaline stability at a wide range of temperature has potential application in the detergent industry.
\end{abstract}

Keywords Bacillus coagulans, lipases, submerged fermentation, detergent compatibility, wash performance

To cite this article: AL-GHANAYEM AA. Purification and characterization of thermo-alkaline stable lipase from Bacillus coagulans and its compatibility with commercially available detergents. Rom Biotechnol Lett. 2021; 26(5): 2994-3001. DOI: 10.25083/rbl/26.5/2994-3001.

*Corresponding author: ABDULLAH A. AL-GHANAYEM, Department of Clinical Laboratory Sciences, College of Applied Medical Sciences Shaqra University, Shaqra 11961 Kingdom of Saudi Arabia.

E-mail: alghanayem@su.edu.sa 


\section{Introduction}

The widespread development of synthetic detergents in recent years has created a negative impact on the environment due to their accumulation in the living organisms, resisting biodegradation etc. [1]. The conventional detergents are not strong enough to wipe out tough stains especially lipid based stains present in the fabrics. Enzyme based detergents are proved and recommended to clean out lipid based stains, as it breaks the organic macromolecules leading to easy removal of stains [2]. Thermostable and alkaline lipases are preferred for detergent applications [3] to improve wash performance, making eco-friendly and energy saving detergent products. The presence of some chemicals in laundry detergent causes to reduce the efficiency of the added lipases and affects the quality of fabrics. For instance, Lipolases (Novozymes Denmark), lost more than $50 \%$ activity in presence of $1.0 \%$ hypochlorite [4]. Studies show, addition of lipase in detergent reduces the usage of chemicals and its adverse effect, making the detergent safer to the environment. [5]. However, more research is needed on lipases to improve their quality to make it more compatible with detergents. There are many factors that affect the activity of lipases when used as an additive in detergent such as surfactant compatibility, thermal and hydrodynamic stability, enzyme kinetics and its activity at the oil water interface [6].

There are many lipases of microbial origin used in industrial applications, only a few have been commercially successful in the detergent formulations [7]. The application of lipase in the detergent industry still gives an urge for searching new lipases with novel properties. Lipases with enhanced activity at high temperature and high stability at alkaline $\mathrm{pH}$ are more suitable for detergent applications. These are developed by microbial screening and rational protein engineering. Using advanced technologies is time consuming and expensive [8]. Proper selection of a wild strain and optimizing a maximum production will provide stable enzymes and help to increase the yield economically. Additionally, these isolates are easily preserved and maintained throughout the process. Till date there are no reports on compatibility of $B$. coagulans lipase with commercially available detergents. In this research, production optimization, purification and characterization of thermostable-alkaline lipase from $B$. coagulans was studied for better understanding of its potential as a detergent additive.

\section{Materials and Methods}

Molecular identification of the bacterial strain: Lipases producing bacterial strains were isolated from soil samples on tributyrin agar plates and selected based on halo zones around the colonies. A potential lipase producing bacterial strain was isolated and maintained as pure culture. Morphological and biochemical identification tests were carried out and further the isolate was identified based on 16S rRNA sequencing. The molecular identification of the strain was done by evolutionary analysis by maximum likelihood method and Tamura-Nei model [9]. To represent the evolutionary history of the taxa, the bootstrap consensus tree inferred from 1000 replicates were used. The tree with the maximum log likelihood is presented in Figure 1. The corresponding branches of partition with bootstrap replicates less than $50 \%$ were collapsed and the percentage associated taxa clustered in bootstrap test are presented subsequent to the branches [10]. Maximum composite like hood (MCL) approach was used to estimate matrix of pairwise distance by applying Neighbor-Join and BioNJ algorithms for initial tree(s) and selecting the topology with superior log likelihood value. Nucleotide sequences were analyzed and 1551 positions were in the final dataset. MEGA X were used for evolutionary analyses [11].

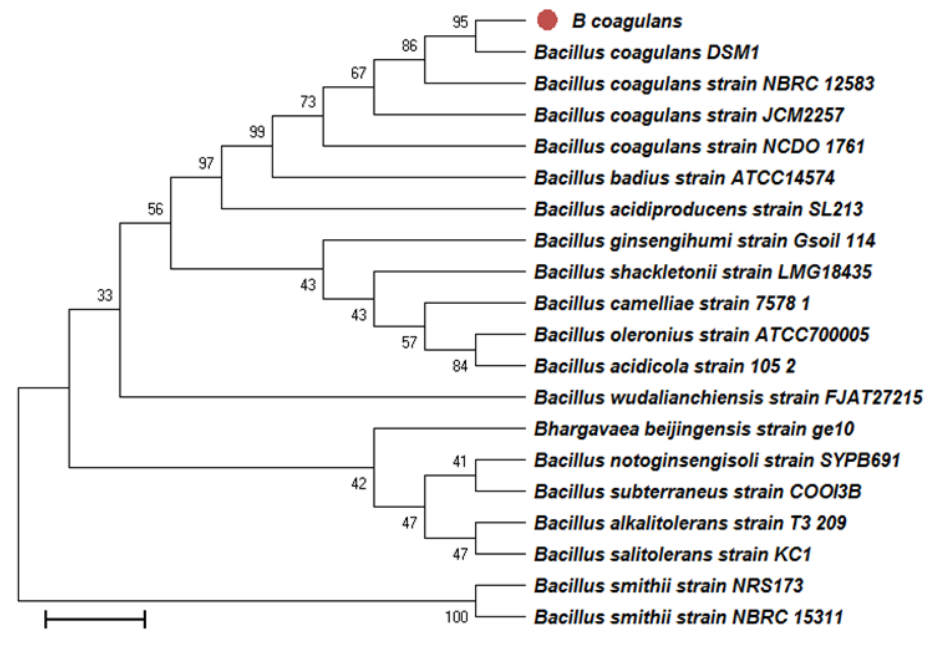

0.010

Figure 1. Molecular identification and phylogenetic analysis of Bacillus coagulans by using maximum likelihood method 
Assay of lipase activity: Lipase assay was done by spectrophotometric assay with $p$-nitro phenyl palmitate ( $p$ NPP) as substrate [12]. Lipase was pre-incubated in phosphate buffer $(90 \mathrm{~mL})$, along with gum arabic $(100 \mathrm{mg})$ and sodium deoxycholate (207 $\mathrm{mg}$ ) containing substrate $p$ NPP (30 mg) dissolved in $10 \mathrm{~mL}$ of isopropanol and was incubated at $37{ }^{\circ} \mathrm{C}$ for $15 \mathrm{~min}$. $p$ NPP released was quantified using a spectrophotometer $(405 \mathrm{~nm})$. One unit of lipase activity was defined as the amount lipase releasing one $\mu \mathrm{mol}$ of $p \mathrm{NP}$ per min under assay condition. For determination of protein levels, bovine serum albumin (BSA) was used as standard [13].

Media optimization: For optimization of media, 100 $\mathrm{mL}$ of lipase production medium (tributyrin broth) was prepared and inoculated with $5 \%$ seed culture. The production of lipase was monitored up to $84 \mathrm{~h}$ at $12 \mathrm{~h}$ intervals. For determining the effect of $\mathrm{pH}$ on lipase production, tributyrin broth (TB) was prepared with $\mathrm{pH}$ values ranging from 6-11 using $1 \mathrm{~N} \mathrm{NaOH}$ or $\mathrm{HCl}$. To study the influence of carbon sources; glucose, mannitol, lactose or sucrose at a concentration of $0.5 \% \mathrm{w} / \mathrm{v}$ were added separately to TB medium. For studying the effect of nitrogen sources, beef extract was replaced with $0.2 \%$ of yeast extract, malt extract, sodium nitrate $\left(\mathrm{NaNO}_{3}\right)$ and ammonium nitrate $\left(\mathrm{NH}_{4} \mathrm{NO}_{3}\right)$. To investigate the influence of lipids as inducers for lipase production, cween 80 , soybean oil, coconut oil and mustard oil were added to the basal medium. The effects of sodium chloride $(\mathrm{NaCl})$, magnesium chloride $\left(\mathrm{MgCl}_{2}\right)$ and potassium chloride $(\mathrm{KCl})$ on lipase production were also tested. All the experiments to evaluate the effect of culture condition and media composition were performed by shake flask culture. The temperature for lipase production was maintained at $37^{\circ} \mathrm{C}$ for $48 \mathrm{~h}$ at $\mathrm{pH} 9$. Triplicate set of experiments were carried out and the mean of three independent trials were recorded as results.

Purification of lipase: The lipase was produced in large amounts under optimized conditions. The crude lipase was collected by centrifuging (10,000 rpm for $10 \mathrm{~min})$ after incubation period. The purification steps were carried out at $4{ }^{\circ} \mathrm{C}$. Initially the lipase was precipitated by adding ammonium sulfate $(20-80 \%)$. The precipitates were collected by centrifugation at $12000 \mathrm{rpm}$ for $20 \mathrm{~min}$. The lipase was re-suspended in $0.05 \mathrm{M}$ of phosphate buffer $(\mathrm{pH}$ 8.0) and dialyzed overnight against the same buffer by changing the buffer three times. For preparation of the column $1.5 \mathrm{~g}$ of dry Sephadex G-100 was suspended in a $50 \mathrm{~mL}$ phosphate buffer and heated $\left(95^{\circ} \mathrm{C}\right)$ in water-bath to get a slurry. The column was filled with slurry and left for $5 \mathrm{~h}$ and then equilibrated with a $50 \mathrm{mM}$ phosphate buffer. The dialyzed fraction of lipase was loaded in a Sephadex G-100 column $(1.0 \times 33 \mathrm{~cm})$. The lipase fractions were eluted by linear gradients of $\mathrm{NaCl}(0.1-1.0 \mathrm{M})$ at a flow rate of $40 \mathrm{mLh}^{-1}$. The fractions $(2 \mathrm{~mL})$ were collected separately and assayed for lipase activity. The fractions with high lipase activity were pooled and used for further characterization.

Characterization of lipases: The purified lipase was characterized for stability and activity at different temperatures, $\mathrm{pH}$, solvent stability, effect of heavy metal ions and inhibitors. Lipase activity at different $\mathrm{pH}$ (7.0 11.0) was measured by using different buffers. For testing the $\mathrm{pH}$ stability, purified lipase mixed with buffers having different $\mathrm{pH}$ (7.0-11.0), the solutions were pre-incubated $\left(37^{\circ} \mathrm{C}\right)$ for $1 \mathrm{~h}$ and assayed for residual activity. To determine the lipase activity at different temperatures, lipase mixture was incubated at $10-80{ }^{\circ} \mathrm{C}$ for $15 \mathrm{~min}$. For testing the stability at various temperatures $\left(10\right.$ to $\left.80{ }^{\circ} \mathrm{C}\right)$, the lipase was incubated for $1 \mathrm{~h}$ and measured for its activity.

Different concentrations ( 5 and $10 \% \mathrm{v} / \mathrm{v}$ ) of solvents were used for detecting the effect of solvents on lipase activity. Methanol, dimethyl sulfoxide (DMSO), dimethyl formamide (DMFO), acetone, hexane, ethanol, isopropanol and butanol were used. Lipase were mixed with these solvents and removed after $1 \mathrm{~h}$ by centrifugation at 10,000 $\mathrm{rpm}$ for $5 \mathrm{~min}$. The lipase activity was measured by standard assay method [14]. Inhibitors at $5 \mathrm{mM}$ and $10 \mathrm{mM}$ concentration such as iodoacetic acid (IAA), sodium dodecyl sulfate (SDS), dithiothreitol (DTT), ethylene diamine tetra acetate (EDTA), ethylene glycol - bis (2 aminoethyl ether - NNN'N' - tetra acetic acid (EGTA), potassium iodide $(\mathrm{KI})$ and $p$ - chloro mercuribenzoic acid $(p \mathrm{CMB})$ were used to determine the inhibition profile of lipase. The mixture was incubated with different inhibitors in a buffer $(\mathrm{pH} 8)$. The relative lipases activity was measured using a control. The effects of heavy metal ions such as, $\mathrm{Cr}^{2+}, \mathrm{Hg}^{2+}, \mathrm{Cd}^{2+}, \mathrm{Fe}^{2+}, \mathrm{Co}^{2+}$ and $\mathrm{Mg}^{2+}$ were investigated by incubating the lipase in $10 \mathrm{mM}$ solutions.

Compatibility with detergent and wash performance analysis: The compatibility of lipase with commercially available laundry detergents was determined. Four detergents namely; Tide (Procter and Gamble), Surf (Unilever), Wheel (Hindustan Unilever Ltd. India) and Ariel (Procter and Gamble) were studied. For inactivation of endogenous enzymes, the detergents were dissolved in distilled water $\left(7 \mathrm{mg} \mathrm{mL}^{-1}\right)$ and heated at $60^{\circ} \mathrm{C}$ for $1 \mathrm{~h}$. The solution was mixed with lipase $(1: 1)$ and kept for $3 \mathrm{~h}$. Lipase assay was carried out after each 30 min interval to determine the residual activity. A control tube with lipase without detergent was taken as $100 \%$. Feasibility of alkaline lipase for additives in detergents was studied using small pieces of cotton cloth $(4 \times 4 \mathrm{~cm})$ stained with different stains such as used engine oil, used kitchen oil and cosmetics (lipstick). The cloth pieces were kept in individual flasks containing water $(100 \mathrm{~mL}), 100 \mathrm{~mL}$ detergent solution (Wheel $7 \mathrm{mgmL}^{-1}$ ) and with $100 \mathrm{ml}$ of detergent solution (Wheel $7 \mathrm{mg} \mathrm{mL}^{-1}$ ) containing $2 \mathrm{~mL}$ lipase enzyme. The setup was kept for $30 \mathrm{~min}$ at normal temperature with agitation. Cloth pieces were taken and washed with water. The pieces were dried to determine brightness and whiteness to test the efficiency of detergent in removing the stains.

\section{Results and Discussion}

The soil samples from oil contaminated sites were used to isolate lipase producing bacteria using tributyrin agar. 
Based on lipase activity, a potential isolate was selected. The bacterial strain was Gram positive rods showing (0.6 to 0.9 by 2.5 to $5.0 \mu \mathrm{m}$ in size), spore forming, motile, facultative anaerobe that grows at a wide range of temperature $\left(20-55^{\circ} \mathrm{C}\right)$. Catalase, methyl red, starch hydrolysis reactions were positive. It produced acid from glucose, mannose, fructose and galactose. Negative for indole, urease, citrate, hydrogen sulfide $\left(\mathrm{H}_{2} \mathrm{~S}\right)$, lysine decarboxylase, ornithine decarboxylase, casein hydrolysis and tryptophan deaminase. It produced acid from arabinose, arabitol, fucose, mannitol, maltose, sorbose and xylose. Further the strain was identified based on molecular methods. The $16 \mathrm{~S}$ rRNA sequence of the isolated strain was used for GenBank BLASTn search. 16S rRNA sequences of several representatives of $B$. coagulans strains were retrieved and a phylogenetic tree was constructed by using Mega-X. Results suggested that it is a sub strain of Bacillus coagulans DSM 1. There are earlier reports on some Bacillus sp. producing lipase by solid state fermentation [15] and submerged fermentations [16]. It has been reported that lipases from Bacillus strain can be produced at low cost with improved thermal stability to withstand harsh environmental conditions [17].

Bacillus coagulans culture was prepared in tributyrin broth $(100 \mathrm{~mL})$ at $37{ }^{\circ} \mathrm{C}$ and the maximum enzyme production was obtained after $48 \mathrm{~h}$ of incubation (Table 1 ). There was a reduction in enzyme production after the optimum time duration. The data obtained clearly indicates $\mathrm{pH}$ of 9 was found suitable lipase production and a strong influence of alkaline $\mathrm{pH}$ on enzyme production was observed. Lactose was the best carbon source utilized by the isolate followed by glucose for lipase production (Table 2). However, mannitol and sucrose were not utilized by the organism as a carbon source. Nitrogen sources; sodium nitrate followed by ammonium nitrate influenced lipase production. Other organic nitrogen sources, such as malt and yeast extract did not have a significant effect on lipase production. Effect of different substrates in the medium for the production of lipase were tested. However, addition of substrates such as cween 80 , soybean oil, coconut oil and mustard oil reduced the production of lipase. Addition of $\mathrm{MgCl}_{2}$ in the medium had a stimulatory effect on lipase production. Other minerals such as $\mathrm{NaCl}$ and $\mathrm{KCl}$ had lesser effect. The production of lipase is known to vary with environmental factors such as temperature, $\mathrm{pH}$ etc. The strain produced lipase within $48 \mathrm{~h}$, at a $\mathrm{pH}$ of 9 . The lipase production reduced after $48 \mathrm{~h}$ of incubation, and this may be due to nutrient depletion in the medium. Bacteria secrete lipase in the late exponential phase [18]. B. coagulans used lactose and sodium nitrate as carbon and nitrogen sources respectively. Cween 80 , soybean oil, coconut oil and mustard oil did not alter the lipase production. Addition of oil might have interfered with growth due to the decreased aeration of the medium. $\mathrm{MgCl}_{2}$ served as a mineral source for production of lipase. This optimization process of enzyme will help for maximum enzyme production at a reduced cost.
Table 1. Effect of incubation time and $\mathrm{pH}$ on alkaline lipase production at $37^{\circ} \mathrm{C}$

\begin{tabular}{lll}
\hline Parameters & & Activity $\left(\mathrm{U} \mathrm{mL}^{-1}\right)$ \\
\hline a) Incubation time (h) & 12 & $0.82 \pm 0.06$ \\
& 24 & $2.15 \pm 0.12$ \\
& 36 & $3.65 \pm 0.15$ \\
& 48 & $5.21 \pm 0.14$ \\
& 60 & $2.34 \pm 0.12$ \\
& 72 & $1.94 \pm 0.15$ \\
& 84 & $1.17 \pm 0.16$ \\
\hline b) $\mathrm{pH}$ & 6 & $3.54 \pm 0.12$ \\
& 7 & $3.95 \pm 0.17$ \\
& 8 & $4.52 \pm 0.18$ \\
& 9 & $5.64 \pm 0.16$ \\
& 10 & $5.18 \pm 0.17$ \\
& 11 & $3.64 \pm 0.15$ \\
\hline
\end{tabular}

Table 2. Effect of supplementation of different carbon, nitrogen, substrates, mineral salts on alkaline lipase production

\begin{tabular}{lll}
\hline Parameters & Sources & Activity $\left(\mathrm{U} \mathrm{mL}^{-1}\right)$ \\
\hline a) Carbon & Glucose & $6.16 \pm 0.16$ \\
& Mannitol & $3.21 \pm 0.08$ \\
& Lactose & $6.63 \pm 0.15$ \\
& Sucrose & $4.18 \pm 0.09$ \\
\hline b) Nitrogen & Yeast extract & $4.51 \pm 0.09$ \\
& Malt extract & $2.65 \pm 0.07$ \\
& $\mathrm{NaNO}_{3}$ & $6.79 \pm 0.19$ \\
& $\mathrm{NH}_{4} \mathrm{NO}_{3}$ & $6.42 \pm 0.14$ \\
\hline b) Substrates & $\mathrm{Cween} 0$ & $1.42 \pm 0.09$ \\
& Soya bean oil & $1.25 \pm 0.05$ \\
& Coconut oil & $1.32 \pm 0.06$ \\
& $\mathrm{Mustard}$ oil & $1.56 \pm 0.04$ \\
\hline c) mineral salts & $\mathrm{NaCl}$ & $5.82 \pm 0.18$ \\
& $\mathrm{MgCl}$ & $8.19 \pm 0.20$ \\
& $\mathrm{KCl}$ & $5.34 \pm 0.15$ \\
\hline
\end{tabular}

For detergent applications partially purified lipases are preferred. Purification was carried out by ammonium sulfate precipitation method, further loaded on Sephadex G-100 column and the fractions were eluted (Table 3). Specific activity of the active fractions in the final step was 906.29 $\mathrm{Umg}^{-1}$ protein with a total protein yield of $2.7 \mathrm{mg}$ with 24.5 purification fold and $30.2 \%$ yield. For effective production and utilization of these enzymes, biochemical characterization and stability studies are required. The optimum $\mathrm{pH}$ for lipase activity was 8 and $80 \%$ of the activity remained at $\mathrm{pH}$ of 10 (Fig. 2). Lipase showed maximum stability at $\mathrm{pH} 8$ and at $\mathrm{pH}$ of 9.5 , only $21 \%$ of stability was lost. The purified lipase was active at $40{ }^{\circ} \mathrm{C}$ and maintained its $90 \%$ activity at $30{ }^{\circ} \mathrm{C}$ after incubating for $1 \mathrm{~h}$ (Fig. 3). Lipase was active even at $20^{\circ} \mathrm{C}$. This results shows that the lipase isolated from $B$. coagulans is a suitable candidate for cold washing. The purified lipase was studied for its stability with solvents (Table 4). The activity was decreased in a concentration dependent manner; with higher the concentration of solvent, the activity and 
stability were decreased. Lipase was more stable with acetone, N, N- dimethylformamide (DMFO) and hexane, whereas, other solvents decreased the stability of lipase.

The effect of inhibitors on lipase was studied and the inhibition similar to that observed with solvents. The stability of lipase in chelating agents, anionic surfactants, nonionic surfactants, bleaches and oxidizing agents are prerequisite for detergent formulations. The chelating agents are responsible for reducing water hardness by chelating ions resulting in efficient removal of stains [19]. In the present study, lipase showed more than $80 \%$ activity in presence of EDTA (1mM). The inhibition of lipase activity was observed with high concentration of inhibitors (Table 5). Iodoacetic acid (IAA) and $p$-CMB (10mM) inhibited $70 \%$ of lipase activity. Other inhibitors such as dithiothreitol (DTT) and ethylene diamine tetra acetic acid (EDTA) inhibited residual lipase activity up to $50 \%$ at $10 \mathrm{mM}$ concentration. However, $<20$ inhibition was observed with other inhibitors such as sodium dodecyl sulfate (SDS), EGTA (ethylene glycol-bis ( $\beta$-aminoethyl ether)-N,N,N',N'-tetra-acetic acid) and potassium iodide (KI). Lipases showing high activity under nonconventional conditions such as high thermal stability, wide $\mathrm{pH}$ stability makes it possible for its use in industries such as chemical, pharmaceutical, dairy, beverages, fats, oil, cosmetics, leather, paper cleaning etc. [20]. Heavy metal inhibition was studied using 1 and $10 \mathrm{mM}$ concentration of the metal ions. Mercury (10mM) was found to be a strong inhibitor for the lipase activity and other metals such as cadmium, ferrous, cobalt and magnesium inhibited $\geq 70 \%$ lipase activity. However, other metal ions such as sodium and chromium inhibited around $50 \%$ activity at $10 \mathrm{mM}$ concentration. Low concentration of metal ions also had inhibitory activity on lipase especially mercury followed by cadmium, ferrous, cobalt and magnesium while low concentration of sodium did not have any noticeable effect on lipase activity.

Lipid stains in the fabric form a stable fabric-lipid complex that is hard to remove and resistant to harsh washing conditions. Lipases compatible with detergent hydrolyses the lipid stain and removes it easily from the fabrics. The detergent compatible lipases should be stable at high $\mathrm{pH}$, water soluble, suitable with detergent proteases and surfactants with low surface stability [19]. Lipase of $B$. coagulans had excellent compatibility and stability with commercially available detergents. Lipase showed more than $70 \%$ stability after $1 \mathrm{~h}$ incubation and more than $50 \%$ stability after $3 \mathrm{~h}$ of incubation (Fig. 4).

Table 3. Summary of purification of lipases isolated from Bacillus coagulans

\begin{tabular}{lllllllll}
\hline $\begin{array}{l}\text { Purification } \\
\text { Step }\end{array}$ & $\begin{array}{l}\text { Volume } \\
(\mathbf{m L})\end{array}$ & $\begin{array}{l}\text { Total } \\
\text { Activity } \\
(\mathbf{U})\end{array}$ & $\begin{array}{l}\text { Total } \\
(\mathbf{m g})\end{array}$ & Protein & $\begin{array}{l}\text { Specific } \\
\left(\mathbf{U m g}^{-1}\right)\end{array}$ & Activity & $\begin{array}{l}\text { Purification } \\
\text { Fold }\end{array}$ & $\begin{array}{l}\text { \% } \\
\text { Yield }\end{array}$ \\
\hline $\begin{array}{l}\text { Crude } \\
\text { enzyme }\end{array}$ & 1000 & 8100 & 219 & 36.98 & 1.0 & 100 \\
$\begin{array}{l}\text { Precipitation } \\
\left(\left(\mathrm{NH}_{4}\right)_{2} \mathrm{SO}_{4}\right)\end{array}$ & 100 & 4858 & 16.1 & 301.73 & 8.1 & 59.97 \\
$\begin{array}{l}\text { Sephadex } \\
\text { G-100 }\end{array}$ & 50 & 2447 & 2.7 & 906.29 & 24.5 & 30.2 \\
\hline
\end{tabular}

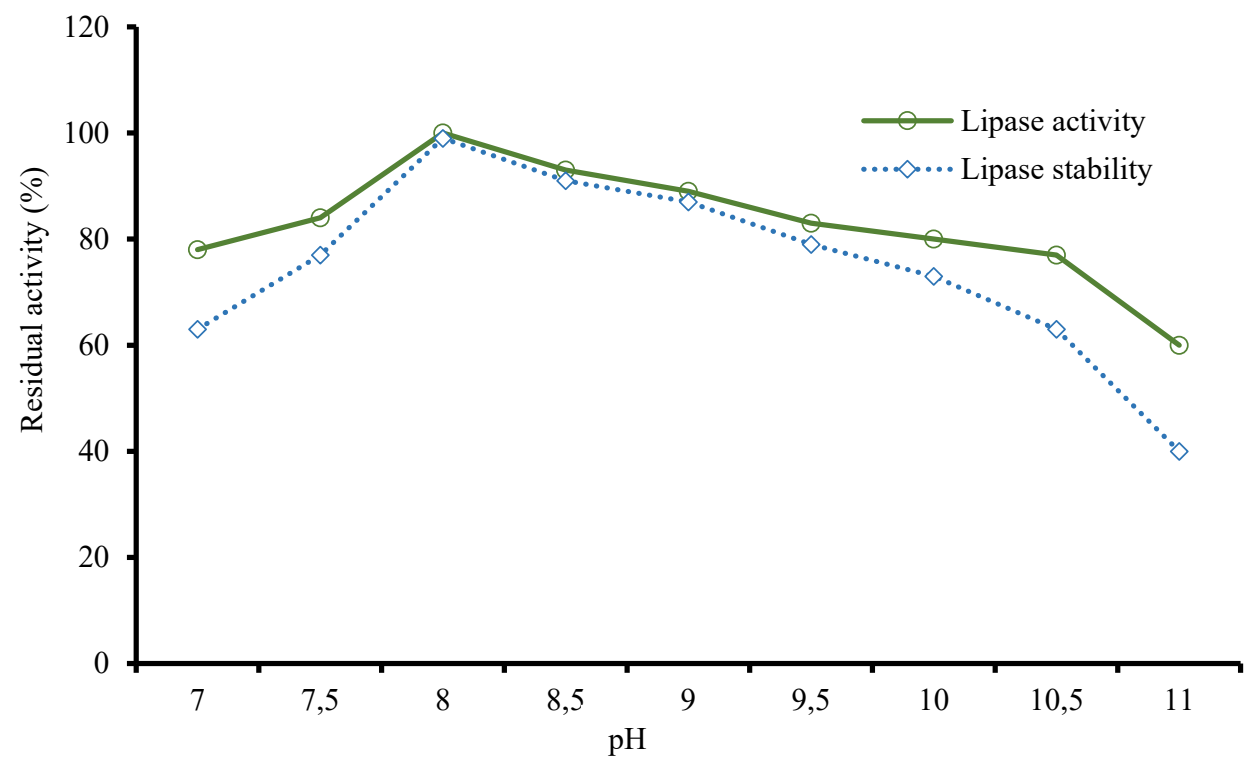

Figure 2. Lipase activity and stability at different $\mathrm{pH}$ 


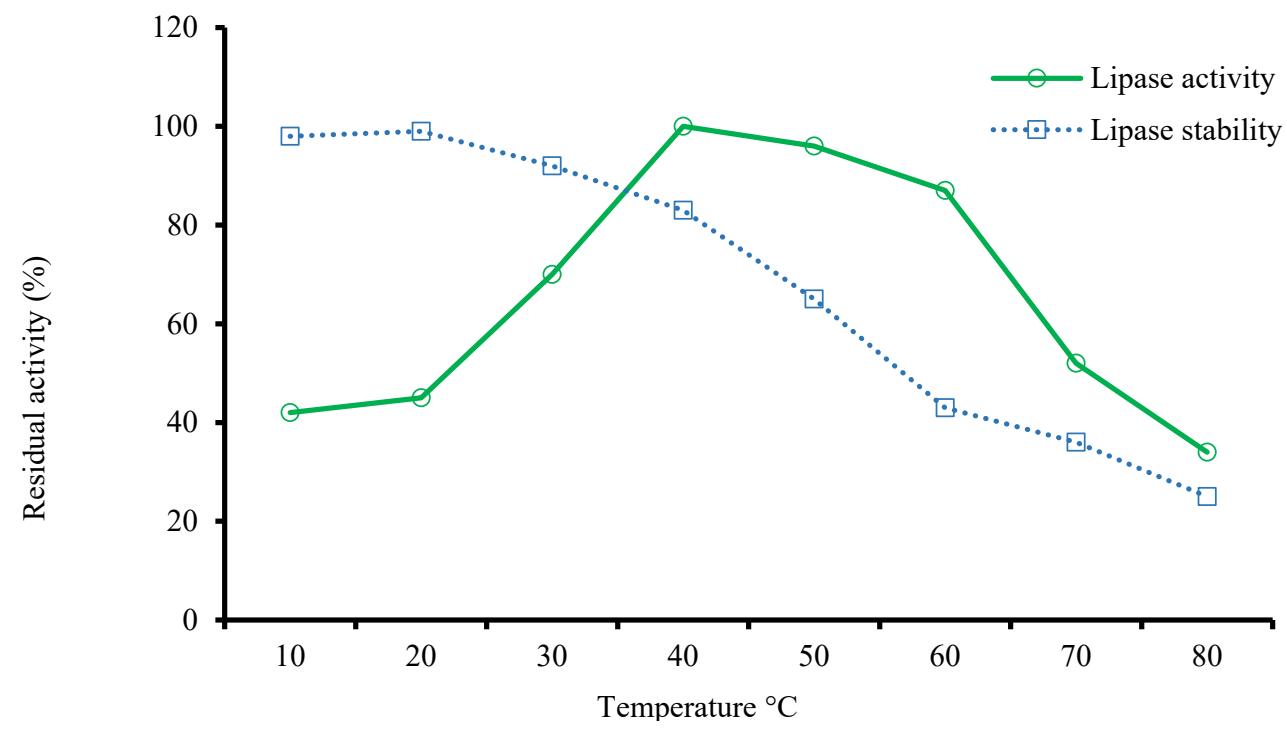

Figure 3. Lipase activity and stability at different temperature

Table 4. Effect of solvents on lipase activity

\begin{tabular}{lll}
\hline Solvents & \multicolumn{2}{c}{$\%$ Residual activity } \\
\cline { 2 - 3 } & $5 \%$ & $10 \%$ \\
\hline Methanol & 49.5 & 37.4 \\
DMSO & 42.7 & 32.1 \\
DMFO & 61.4 & 42.6 \\
Acetone & 69.7 & 43.8 \\
Hexane & 68.5 & 41.2 \\
Ethanol & 57.4 & 35.8 \\
Isopropanol & 52.7 & 33.4 \\
Butanol & 54.2 & 32.9 \\
\hline
\end{tabular}

Table 5. Effect of inhibitors and heavy metals on lipase activity

\begin{tabular}{llll}
\hline & & \multicolumn{2}{c}{$\%$ Residual Activity } \\
\cline { 3 - 4 } Inhibitors & & $1 \mathrm{mM}$ & $10 \mathrm{mM}$ \\
\hline & IAA & 35.8 & 31.5 \\
& SDS & 97.5 & 95.2 \\
& DTT & 58.4 & 47.3 \\
& EDTA & 87.3 & 54.3 \\
& EGTA & 91.5 & 87.9 \\
& KI & 98.5 & 82.7 \\
& $p C M B$ & 32.2 & 27.6 \\
\hline Heavy metals & $\mathrm{Cr}^{2+}$ & 54.8 & 46.2 \\
& $\mathrm{Hg}^{2+}$ & 19.07 & 07.5 \\
& $\mathrm{Cd}^{2+}$ & 30.77 & 25.3 \\
& $\mathrm{Fe}^{2+}$ & 30.67 & 22.9 \\
& $\mathrm{Co}^{2+}$ & 31.26 & 24.7 \\
& $\mathrm{Mg}^{2+}$ & 30.88 & 26.9 \\
\hline
\end{tabular}

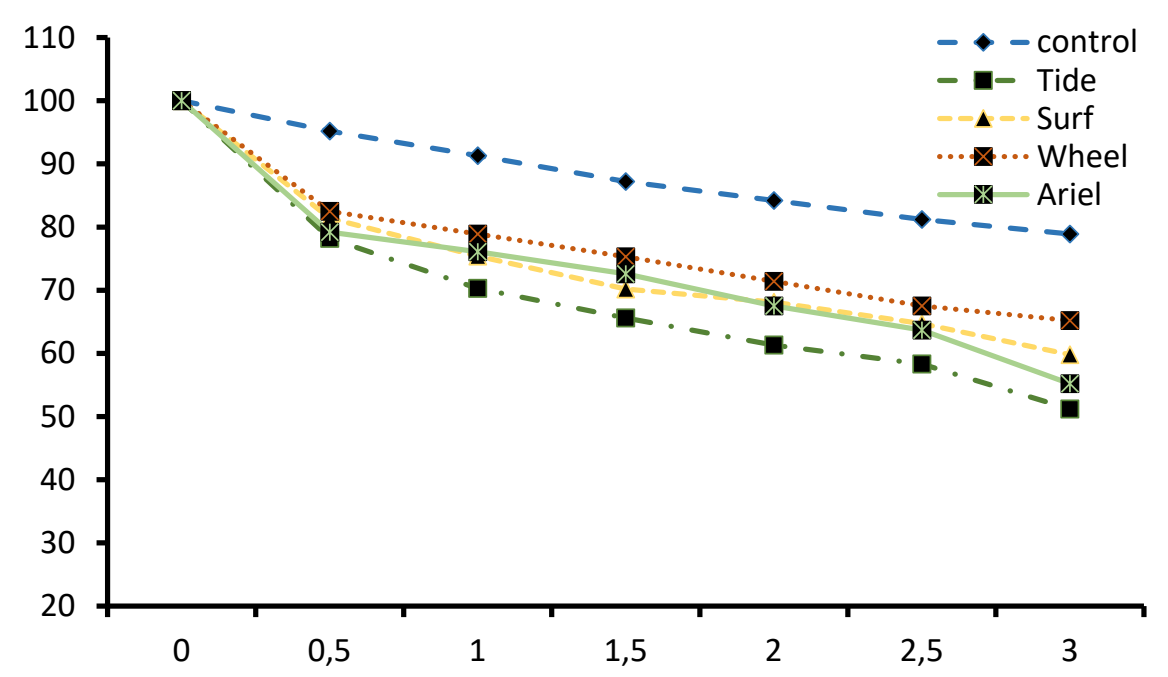

Figure 4. Compatibility of Bacillus coagulans lipase with commercially available detergent. 
Engine oil stained clothes were washed with detergent with lipase increased brightness and whiteness of the fabric when compared to the control. The fabrics treated with kitchen waste oil washed in detergent with lipase increased the brightness and whiteness. Similar result was observed with cosmetic stained fabric that was washed using detergent with lipase (Table 6).

Table 6. Brightness and whiteness of stained fabrics washed with water without detergent, water with detergent and lipase added detergent

\begin{tabular}{llll}
\hline \multirow{2}{*}{ Stains } & Treatments & \multicolumn{2}{l}{ Reflectance (\%) } \\
\cline { 3 - 4 } & & Brightness & Whiteness \\
\hline Engine oil & water & 4.8 & 6.7 \\
& Detergent + water & 5.2 & 9.2 \\
& Lipases + Detergent + water & 9.6 & 16.5 \\
\hline Kitchen waste oil & water & 6.2 & 9.6 \\
& Detergent + water & 8.7 & 10.3 \\
& Lipases + Detergent + water & 10.9 & 19.1 \\
\hline Cosmetics & water & 5.7 & 7.4 \\
(lipstick) & Detergent + water & 6.3 & 9.7 \\
& Lipases + Detergent + water & 10.6 & 18.9 \\
\hline
\end{tabular}

This result supports the use of thermo-alkaline stable lipases as an additive to improve wash performance of detergents. Utilization of bacterial lipases in industrial processes especially in detergents have been reported earlier [3]. However, for improving the efficiency of detergents, a thermostable alkaline stable lipase is needed that can withstand the alkaline $\mathrm{pH}$ and has an increased shelf-life. Amongst the bacterial lipases, only few were reported for thermo-alkaline stable lipases [21, 22]. $B$. coagulans has been reported for production of both metallo and alkaline lipases earlier [23-25]. These lipases break the carboxyl ester bonds of triglycerols and liberate fatty acid and glycerol. Thereby, multifaceted properties of lipase makes it a potential tool for industrial and biotechnological applications [26]. Addition of enzymes help to remove fuzz and pills from the fabrics and assist to protect color of the fabrics. Further, the effectiveness of enzyme at a minimum concentration with improved stability at high temperatures and good biodegradability without leaving any harmful residues that benefits the environment.

\section{Conclusion}

A thermostable alkaline stable lipase from B. coagulans was produced and studied for its characterization. The lipase was stable at high $\mathrm{pH}$ and temperature and was found to be compatible with detergent that increased the brightness and whiteness of the test cotton fabrics. The newly isolated lipases satisfied the basic requirements for detergent additive. This enzyme with high alkaline and thermal stability, activity at a wide range of temperature may have significant application in detergent the industry.

\section{Acknowledgement}

The author wishes to thank Dr. Babu Joseph for providing the samples and technical aid for carrying out the study.

\section{Ethical approval}

This study does not involve any animal or human subjects.

\section{Disclosure statement}

The author declares that there is no conflict of interest.

\section{Funding}

There was no financial support for the research.

\section{References}

1. BORAN R. Detergent compatible extracellular lipase from Streptomyces cellulosae AU-10: A green alternative for the detergent industry. J. Surfactants Deterg., 2018; 21: 565-573.

2. RAHSE W. Production of tailor-made enzymes for detergents. ChemBioEng Reviews, 2014; 1(1): 27-39.

3. ZARINVIARSAGH M, EBRAHIMIPOUR $\mathrm{G}$, SADEGHI H. Lipase and biosurfactant from Ochrobactrum intermedium strain MZV101 isolated by washing powder for detergent application. Lipids Health Dis., 2017; 16: 177.

4. NIYONZIMA FN, MORE SS. Microbial detergent compatible lipases. J. Sci. Ind. Res., 2015; 74(2): 105113.

5. GIAGNORIO M, AMELIO A, GRUTTNER H, TIRAFERRI A. Environmental impacts of detergents and benefits of their recovery in the laundering industry. J. Clean Prod., 2017; 154: 593-601.

6. JURADO E, GARCIA-ROMAN M, LUZON G, ALTMAJER-VAZ D, JIMENEZ-PEREZ JL. 
Optimization of lipase performance in detergent formulations for hard surfaces. Ind. Eng. Chem. Res., 2011; 50: 11502-11510.

7. RAVEENDRAN S, PARAMESWARAN B, UMMALYMA SB, ABRAHAM A, MATHEW AK, MADHAVAN A, et al. Applications of microbial enzymes in food industry. Food Technol. Biotech., 2018; 56: 16-30.

8. GUPTA A, JOSEPH B, MANI A, THOMAS G. Biosynthesis and properties of an extracellular thermostable serine alkaline protease from Virgibacillus pantothenticus. World J. Microbiol. Biotechnol., 2008; 24(2): 237-243.

9. TAMURA K, NEI M. Estimation of the number of nucleotide substitutions in the control region of mitochondrial DNA in humans and chimpanzees. Mol. Biol. Evol., 1993; 10: 512-526.

10. FELSENSTEIN J. Confidence limits on phylogenies: An approach using the bootstrap. Evolution, 1985; 39: 783-791.

11. KUMAR S, STECHER G, LI M, KNYAZ C, TAMURA K. MEGA X: Molecular Evolutionary Genetics Analysis across computing platforms. Mol. Biol. Evol. 2018; 35: 1547-1549.

12. WINKLER UK, STUCKMANN M. Glycogen, hyaluronate, and some other polysaccharides greatly enhance the formation of exolipase by Serratia marcescens. J. Bacteriol. 1979; 138: 663-670.

13. LOWRY OH, ROSEBROUGH NJ, FARR AL, RANDALL RJ. Protein measurement with the Folin phenol reagent. $J$ Biol Chem., 1951; 193(1): 265-275.

14. JOSEPH B, RAMTEKE PW. Extracellular solvent stable cold-active lipase from psychrotrophic Bacillus sphaericus MTCC 7526: partial purification and characterization. Ann Microbiol., 2013; 63: 363-370.

15. ALKAN H, BAYSAL Z, UYAR F, DOGRU M. Production of lipase by a newly isolated Bacillus coagulans under solid-state fermentation using melon wastes. Appl. Biochem. Biotechnol., 2007; 136: 183192.

16. SUCI M, ARBIANTI R, HERMANSYAH H. Lipase production from Bacillus subtilis with submerged fermentation using waste cooking oil. IOP Conf. Ser. Earth Environ. Sci., 2018; 105: 1-6.

17. RATHI PC, JAEGER KE, GOHLKE H. Structural rigidity and protein thermostability in variants of lipase A from Bacillus subtilis. PLOS One, 2015; 10(7): e0130289.

18. CHEN F, CUI G, WANG S, NAIR MKM, HE L, QI $\mathrm{X}$, et al. Outer membrane vesicle-associated lipase FtlA enhances cellular invasion and virulence in Francisella tularensis LVS. Emerg. Microbes Infect., 2017; 6: e66.

19. SAHAY S, CHOUHAN D. Study on the potential of cold-active lipases from psychrotrophic fungi for detergent formulation. Journal of Genetic Engineering and Biotechnology, 2018; 16(2): 319325.

20. KUMAR B, PRATIVA S, NANDA K, SAHOO S. Characterization of biotechnologically relevant extracellular lipase produced by Aspergillus terreus NCFT 4269.10 Braz. J. Microbiol., 2016; 47(1): 143149.

21. SHARMA R, SONI SK, VOHRA, RM, GUPTA LK, GUPTA JK. Purification and characterization of a thermostable alkaline lipase from a new thermophilic Bacillus sp. RSJ-1. Process Biochem., 2002; 37(10); 1075-1084.

22. BACHA AB, MOUBAYED NM, ABID I. Thermostable, alkaline and detergent-tolerant lipase from a newly isolated thermophilic Bacillus stearothermophilus. Indian J. Biochem. Biophys., 2015; 52(2):179-188.

23. KUMAR S, KIKON K, UPADHYAY A, KANWAR SS, GUPTA R. Production, purification, and characterization of lipase from thermophilic and alkaliphilic Bacillus coagulans BTS-3. Protein Expr. Purif., 2005; 41: 38-44.

24. LiAnghuA T, LIMING X. Purification and partial characterization of a lipase from Bacillus coagulans ZJU318. Appl. Biochem. Biotech., 2005; 125: 139-146.

25. KANWAR SS, GHAZI IA, CHIMNI SS, JOSHI GK, RAO GV, KAUSHAL RK, et al. Purification and properties of a novel extra-cellular thermotolerant metallolipase of Bacillus coagulans MTCC-6375 isolate. Protein Expr. Purif., 2006; 46: 421-428.

26. SARASWAT R, VERMA V, SISTLA S, BHUSHAN I. Evaluation of alkali and thermotolerant lipase from an indigenous isolated Bacillus strain for detergent formulation. Electron J. Biotechnol., 2017; 30: 33-38. 